\title{
Oral hygiene and health-related quality of life in institutionalized older people
}

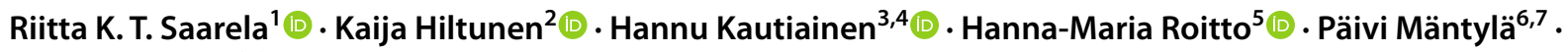 \\ Kaisu H. Pitkälä8,9
}

Received: 28 April 2021 / Accepted: 16 July 2021 / Published online: 27 July 2021

(c) The Author(s) 2021

\section{Key summary points}

Aim We evaluated oral hygiene level and its association with oral health and general health-related quality of life (HRQoL) among older residents in long-term care facilities.

Findings Only one-fifth of residents had good oral hygiene. Poor oral hygiene was associated with poor oral health and diminished HRQoL.

Message Oral hygiene, oral health, and HRQoL may be improved with oral care education of caregivers, professional cooperation, and regular oral healthcare of older residents in long-term care facilities.

\begin{abstract}
Purpose We evaluated the level of oral hygiene and its association with oral health status and need for oral treatment among older residents in long-term care facilities. In addition, the association between oral hygiene level and health-related quality of life (HRQoL) was explored.

Methods This cross-sectional study assessed 231 dentate residents in long-term care facilities ( $71 \%$ female, mean age 81 years, $70 \%$ had dementia). Nurses assessed residents and completed questionnaires on participants' background information, diagnoses, oral healthcare habits, and HRQoL with the 15D instrument. Two qualified dentists performed clinical oral examinations (number of teeth, plaque index, periodontal condition, open caries lesions, and dry mouth). We used a modified plaque index (PI) to measure the level of oral hygiene (good, moderate, and poor) and calculated the clinical Asymptotic Dental Score (ADS) to determine the oral inflammation burden.

Results Of the residents, $21 \%$ had good, $35 \%$ moderate, and $44 \%$ poor oral hygiene according to PI. Poor oral hygiene was associated with poorer cognitive status $(P=0.010)$ and higher oral inflammation burden $(P<0.001)$. Moreover, poor oral hygiene was associated with poorer HRQoL in a correlation analysis adjusted for age and gender.

Conclusions Oral hygiene of older individuals in long-term care is insufficient. Poor oral hygiene is a marker for poor HRQoL. Residents also have a high burden of oral inflammatory diseases and a need for dental care. Older residents' oral hygiene and HRQoL may be improved with oral care education of caregivers and regular dental check-ups.
\end{abstract}

Keywords Aged $\cdot$ Institutional care $\cdot$ Oral hygiene $\cdot$ Health-related quality of life

\section{Introduction}

Riitta K. T. Saarela

riitta.saarela@hel.fi

Kaisu H. Pitkälä

kaisu.pitkala@helsinki.fi

Extended author information available on the last page of the article
Oral health is an important component of health, well-being, and quality of life. Edentulousness has decreased and most older people, also those residing in long-term care facilities, have some of their natural teeth left $[1,2]$. However, about two in five residents in long-term care settings are edentulous [2-6]. In assessing oral health, the most common measurements have been number of present teeth and prevalence of oral diseases such as dental caries, periodontitis, 
and mucosal infections [7]. Of the dentate, $40-77 \%$ have caries [3-5], and periodontal disease is very common [4, 6] in institutional settings. The new definition of oral health is multi-faceted and includes the ability to speak, smile, smell, taste, touch, chew, swallow, and convey a range of emotions through facial expressions with confidence and without pain, discomfort, or disease of the craniofacial complex [8]. Oral cleanliness is crucial in maintaining good oral health and the basis for prevention of oral diseases among older residents in long-term care facilities.

Oral hygiene is poor among vulnerable, care-dependent institutionalized older people [4-6, 9], particularly among those residents needing assistance with oral hygiene [10, 11]. This situation could be explained by many staff-related factors such as high workload, lack of time, poor attitudes, and lack of knowledge regarding the importance of oral hygiene in prevention of oral diseases [12,13]. In addition, some resident-related characteristics, such as self-determination, care-resistant behavior, and low level of cooperation, may be barriers to maintaining daily oral hygiene [3, 14]. There is some evidence that carers' education may improve oral hygiene among care-dependent nursing home residents $[15,16]$. Oral health and oral health-related quality of life (OHRQoL) among institutionalized older people are increasingly being investigated [17]. Previous studies have reported poor OHRQoL among institutionalized older residents due to their generally poor oral health $[3,18]$. However, studies exploring the role of oral cleanliness in general healthrelated quality of life (HRQoL) in this specific population are lacking. The aim of this study was to explore oral hygiene level, oral health status, and need for oral treatment among older residents in long-term care facilities. Another aim was to assess how oral hygiene level is associated with oral diseases and HRQoL.

\section{Materials and methods}

This study is part of a larger project exploring the nutritional status and quality of nutritional care among long-term care residents in Helsinki, Finland. All residents aged 65 years and over who were permanently living $(N=3673)$ in longterm care settings (nursing homes and assisted living facilities) in Helsinki were approached to participate. The participation rate was $68 \%(N=2482)$. Registered nurses most familiar to the residents collected the nutrition data in March 2017. They received thorough training in all assessment protocols before data collection. The questionnaire included items on demographic factors, health and functional status, medical history, oral care, and HRQoL.

They also retrieved dementia diagnosis and use of medication from medical records. Nurses used the Mini-Mental State Examination (MMSE) to assess participants' cognition
[19] and the Clinical Dementia Rating (CDR) "Personal care item" [20] to assess dependence on activities of daily living (ADL). Nurses assessed residents' nutritional status using the Mini Nutritional Assessment (MNA) [21], which is an 18-item tool used to assess nutritional risk (0-30 points). MNA score $<17$ indicates malnourishment, a score between 17 and 23.5 indicates risk for malnourishment, and a score $>23.5$ indicates good nutritional status.

Residents' HRQoL was measured using the 15D quality of life instrument [22]. The 15D is a generic, comprehensive, 15-dimension, standardized measure of HRQoL that can be self-administered or proxy-rated. We used it both as a profile and as a single index score measure. It consists of 15 dimensions (mobility, vision, hearing, breathing, sleeping, eating, speech, excretion, usual activities, mental function, discomfort and symptoms, depression, distress, vitality, and sexual activity) with five ordinal levels. The single index score of the $15 \mathrm{D}$ instrument ranges from 0 to 1 and represents the overall HRQoL.

Nurses assessed residents' frequency of tooth brushing with the following question: "Are the resident's teeth/dentures brushed daily independently or with help?" (yes/no). Similarly, nurses evaluated residents' swallowing difficulties with a yes/no question. The use of oral healthcare services was assessed with the question: "When was the last oral examination performed by a dentist or a dental hygienist?" The responses were categorized as follows: $1=$ less than 1 year ago; $2=1-3$ years ago; $3=$ more than 3 years ago.

\section{Clinical oral examination}

In 2018-2019, two qualified and calibrated dentists performed a comprehensive clinical oral examination on a random sample of 393 residents. Residents gave informed consent also to the oral health study (FINORAL-Finnish Oral Health Study in Long-Term Care). Calibrated dentists carried out a clinical oral examination in long-term care settings with participants lying in their bed or sitting in a chair during the oral examination. Dentists used a mouth mirror and a WHO probe, and they were equipped with loupes (Merident Optergo MO Ultralight Flip-up) and an attached headlamp (Merident Optergo DeLight LED). The clinical oral examination included recording the number of teeth, plaque index, periodontal condition (gingival index, bleeding on probing, periodontal pocket depth measurements), open caries lesions visible to the naked eye, and dryness of the mouth.

Residents were assessed as dentate if she/he had at least one visible tooth. Over half of the examined residents $(N=231)$ were classified as dentate. We divided these dentate participants into three groups according to the amount of dental plaque. We used a modified Silness-Löe [23] plaque index (PI) to measure the level of 
oral hygiene: $0=$ no plaque, $1=$ thin plaque layer at the gingival margin, only detectable by scraping with a probe; $2=$ moderate layer of plaque along the gingival margin, interdental spaces free, but plaque visible to the naked eye; $3=$ abundant plaque along the gingival margin, interdental spaces filled with plaque; $4=$ whole tooth crown covered with plaque, and calculated the mean value for each resident. PI $<2$ indicates good oral hygiene, 2-2.9 moderate oral hygiene, and $\geq 3$ poor oral hygiene.

The dentists also visually assessed whether food debris was present in the subject's mouth. Dentists clinically evaluated signs of dryness in the mouth (modified from Osailan et al. [24]): normal salivation, reduced salivation (mirror sticks to buccal mucosa or tongue, frothy saliva), or dry mouth (glassy appearance of oral palate, lobulated/fissured tongue). The dentists registered open caries lesions visible to the eye. Periodontal condition was measured with gingival index (GI; $0=$ no inflammation to $3=$ severe gingival inflammation), periodontal pocket depth (PPD) registered as the deepest PPD finding for each tooth ( $<4 \mathrm{~mm}, 4-5 \mathrm{~mm}, \geq 6 \mathrm{~mm}$ ), and bleeding on probing (BOP; yes/no for each tooth) and further calculated as the percentage of BOP-positive teeth. We calculated the oral inflammation burden by means of a clinical Asymptotic Dental Score (ADS) (modified from Janket et al. [25]) (Table 1). Points determining the index number of ADS were given according to the severity of the disease/sign. The sum of the assigned points (0-9) was the final ADS score; ADS 0-2 indicated no or low, 3-4 moderate, and 5-9 high asymptomatic oral inflammation burden.

Datasets of the FINORAL and original Helsinki Nutrition Study were then combined. Thus, we obtained background information, nutritional status, clinical oral examination, and $15 \mathrm{D}$ data for 231 dentate residents.

\section{Statistical analysis}

Data are expressed as mean and standard deviation (SD) or counts with percentages. The linearity across the three PI groups was evaluated using the Cochran-Armitage test (Chi-square test for trend), logistic models, and analysis of variance with an appropriate contrast (orthogonal). In case of violation of assumptions (e.g., non-normality), a bootstrap-type test was used. Adjusted correlation coefficients between the PI and dimensions of 15D were calculated by using Spearman's rank correlation method. The normality of variables was evaluated graphically and by using the Shapiro-Wilk W test. The Stata 16.1, StataCorp LP (College Station, TX, USA) statistical package was used for the analysis.

\section{Results}

Residents' mean age was 81 years, $71 \%$ were female, and one-third had a low level of education ( $<8$ years). Of residents, $70 \%$ had diagnosed dementia and $86 \%$ needed much assistance in personal care according to the CDR. About $14 \%$ of the residents were malnourished. According to nurses' assessment, $18 \%$ had swallowing difficulties (Table 2).

Of the residents, $21 \%(N=48)$ had good oral hygiene, whereas $35 \%(N=81)$ had moderate and $44 \%(N=102)$ poor oral hygiene according to the PI. The level of oral hygiene was significantly associated with dementia $(P=0.015)$ and poorer cognitive status $(P=0.010)$. The mean MMSE score of the residents with good oral hygiene was 16.5. The corresponding figures for the moderate and poor hygiene groups were 13.9 and 12.8, respectively. According to nurses' assessment, almost all residents (91\%) had their teeth brushed daily, although less than one-fifth (19\%) brushed
Table 1 Clinical Asymptotic Dental Score (ADS)

\begin{tabular}{ll}
\hline Variable & Points \\
\hline Retained root remnants & $0=$ no root remnant \\
& $1=$ one root remnant \\
$2=\geq 2$ root remnants \\
Gingivitis & $0=$ no gingivitis \\
& $1=$ gingivitis \\
Deepened periodontal pockets (number of teeth with probing depth, PD, 4-5 mm & $0=$ no pockets \\
plus weighted number of teeth with PD $\geq 6 \mathrm{~mm}$ & $1=1-3$ pockets \\
& $2=4-10$ pockets \\
& $3=\geq 11$ pockets \\
Dental caries/edentulism & $0=$ no caries \\
& $1=1-3$ caries lesions \\
& $2=4-7$ caries lesions \\
& or one toothless jaw \\
& $3=\geq 8$ caries lesions \\
\hline
\end{tabular}


Table 2 Characteristics of the residents in long-term care facilities divided into groups according to plaque index (PI) and the level of oral hygiene

\begin{tabular}{|c|c|c|c|c|}
\hline Characteristic & $\begin{array}{l}\mathrm{PI}<2 \\
\text { Good oral hygiene } \\
N=48\end{array}$ & $\begin{array}{l}\text { PI } 2-<3 \\
\text { Moderate oral hygiene } \\
N=81\end{array}$ & $\begin{array}{l}\mathrm{PI} \geq 3 \\
\text { Poor oral hygiene } \\
N=102\end{array}$ & $P$ value* \\
\hline \multicolumn{5}{|l|}{ Nurses' assessment } \\
\hline Age, mean (SD) & $81(8)$ & $81(9)$ & $81(9)$ & 0.83 \\
\hline Female, $N(\%)$ & $32(67)$ & $58(73)$ & $75(74)$ & 0.42 \\
\hline Education, $<8$ years, $N(\%)$ & $17(39)$ & $30(39)$ & $32(36)$ & 0.71 \\
\hline Dementia, $N(\%)$ & $28(58)$ & $55(68)$ & $79(77)$ & 0.015 \\
\hline MMSE, mean (SD) & $16.5(6.8)$ & $13.9(7.7)$ & $12.8(7.0)$ & 0.010 \\
\hline CDR- requires much help with personal care, $N(\%)$ & $35(80)$ & $71(91)$ & $93(91)$ & 0.073 \\
\hline Number of continuous medications, mean (SD) & $9.6(3.4)$ & $9.7(3.9)$ & $8.0(3.3)$ & 0.002 \\
\hline MNA, $N(\%)$ & & & & 0.052 \\
\hline$\geq 24$ (good nutritional status) & $11(25)$ & $17(23)$ & $11(12)$ & \\
\hline $17-23$ (risk of malnutrition) & $28(64)$ & $45(62)$ & $65(71)$ & \\
\hline$<17$ (malnutrition) & $5(11)$ & $11(15)$ & $16(17)$ & \\
\hline Swallowing difficulty, $N(\%)$ & $9(20)$ & $15(20)$ & $18(19)$ & 0.89 \\
\hline Daily toothbrushing, $N(\%)$ & $45(94)$ & $73(91)$ & $92(91)$ & 0.62 \\
\hline $\begin{array}{l}\text { Latest oral examination performed by a dentist/dental } \\
\text { hygienist less than } 1 \text { year ago, } N(\%)\end{array}$ & $27(56)$ & $36(44)$ & $43(42)$ & 0.13 \\
\hline HRQoL index score, mean (SD) & $0.650(0.148)$ & $0.628(0.120)$ & $0.613(0.125)$ & 0.098 \\
\hline \multicolumn{5}{|l|}{ Dentists' clinical oral examination } \\
\hline Number of teeth, mean (SD) & $15.4(7.9)$ & $14.1(8.3)$ & $12.8(8.0)$ & 0.058 \\
\hline Brushing teeth independently, $N(\%)$ & $14(30)$ & $15(19)$ & $16(16)$ & 0.069 \\
\hline Food depris, $N(\%)$ & $19(40)$ & $44(56)$ & $69(70)$ & $<0.001$ \\
\hline BOP, $\%$ & $70(36)$ & $84(29)$ & $91(25)$ & $<0.001$ \\
\hline Caries, $N(\%)$ & $21(46)$ & $48(62)$ & $63(62)$ & 0.092 \\
\hline Reduced salivation, $N(\%)$ & $32(68)$ & $59(75)$ & $81(82)$ & 0.060 \\
\hline ADS, mean (SD) & $3.2(1.7)$ & $4.0(1.7)$ & $4.5(1.8)$ & $<0.001$ \\
\hline
\end{tabular}

$S D$ standard deviation; MMSE Mini Mental State Examination; CDR Clinical Dementia Rating Scale; MNA Mini Nutritional Assesment; $H R Q o L$ Health Related Quality of Life; BOP Bleeding on probing; ADS Clinical Asymptomatic Dental Score

* $P$ for linearity

their teeth independently. Less than half of the residents had undergone an oral examination within the past year.

In dentists' examination, the residents had an average of 13.8 (SD 8.1) teeth left. Of the residents, $57 \%$ had open caries lesions visible to the naked eye. These oral problems were equally common at all oral hygiene levels. According to dentists' clinical evaluation, $74 \%$ of the residents had reduced salivation. Over half of the subjects (57\%) had food debris in their mouth, and it was linearly associated with oral hygiene $(P<0.001)$. In the group of residents with good oral hygiene, the mean prevalence of BOP-positive teeth was $70 \%$. The corresponding figures in the moderate and poor oral hygiene groups were $84 \%$ and $91 \%$, respectively $(P<0.001)$. The burden of oral inflammatory diseases in residents according to ADS was associated with the level of oral hygiene $(P<0.001)$. In residents with good oral hygiene, the mean ADS score was 3.2. The corresponding figures in the moderate and poor oral hygiene groups were 4.0 and 4.5 , respectively.

Total 15D score did not differ between the oral hygiene groups. Figure 1 shows the results from the partial correlation analysis between the PI as a continuous variable and the dimensions of the 15D adjusted for age and gender. Total $15 \mathrm{D}$ score was negatively correlated with the plaque index. Of the dimensions, speech, usual activities, mental function, and sexual activity were negatively correlated with plaque index.

\section{Discussion}

Among long-term care residents, only one in five had good oral hygiene according to the plaque index, whereas $35 \%$ had moderate and $44 \%$ poor oral hygiene. Periodontal level 


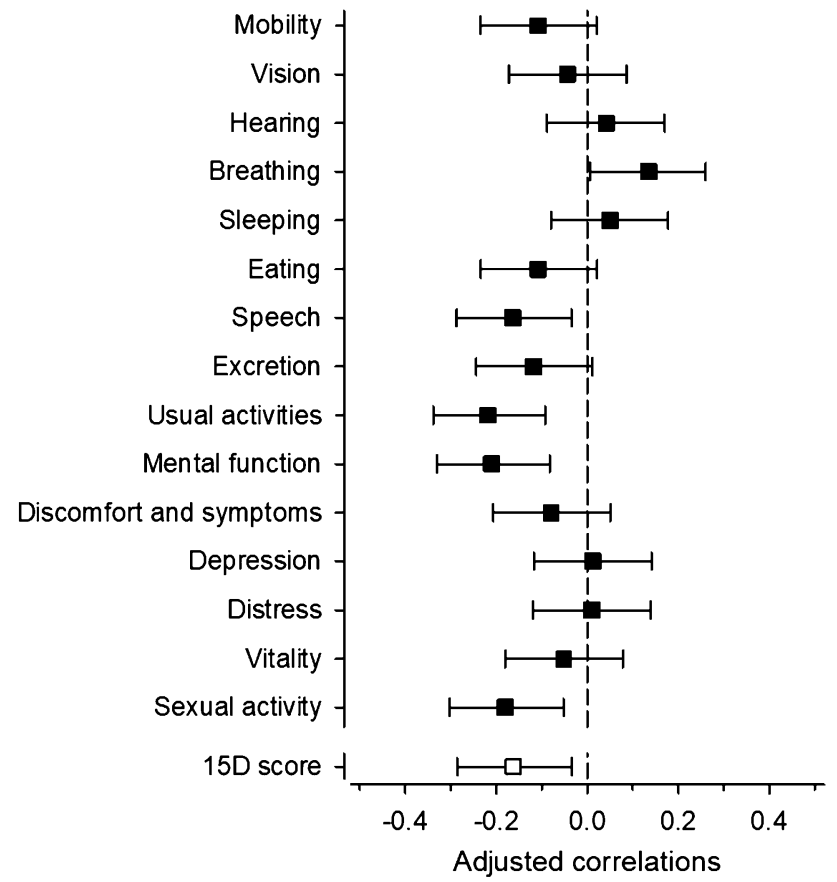

Fig. 1 Spearman's correlations with 95\% confidence intervals between plaque index and dimensions of $15 \mathrm{D}$ adjusted for age and gender

of inflammation measured by BOP seemed poor because most of the teeth (70-91\%) had a positive BOP finding in all oral hygiene groups. Oral inflammation burden according to ADS was on average moderate. Of the residents, $57 \%$ had open caries lesions, which is one component of ADS. These findings indicate poor oral health and a great need for oral treatment. HRQoL according to $15 \mathrm{D}$ score was negatively correlated with the plaque index.

A strength of our study is that two qualified and calibrated dentists performed thorough clinical oral examinations and determined PI to measure the level of oral hygiene. In addition, we used well-validated instruments, such as MNA, MMSE, CDR, and 15D, in data collection and well-trained nurses to collect the data. We also used a structured questionnaire validated in previous nutritional studies in Helsinki in 2003-2011 [26]. To our knowledge, this is the first study to explore general HRQoL and its relationship with oral hygiene in institutional settings. A limitation of our study is its cross-sectional design, which makes it impossible to draw causal relationships between the level of oral hygiene and its associated factors and HRQoL. Another limitation is that HRQoL was evaluated by proxies who may overestimate the impact of cognitive decline on HRQoL compared to participants [27]. However, 15D can be self-reported or evaluated by proxy [22].

In line with earlier studies, poor oral hygiene [4, 6] and oral diseases were common in our study population [17].
More than half of the residents had at least one open caries lesion, consistent with other studies [3-5]. Gingival bleeding is a sign of inflammation of periodontal tissues, and it can reflect gingivitis or periodontitis. In both cases, accumulation of dental plaque is a key contributing factor. In this study, however, deepened periodontal pockets were included in the ADS calculation and were not specifically reported. There is evidence that periodontitis is a risk factor for general health and diseases such as coronary heart disease and atherosclerosis [28]. In accord with earlier research, the prevalence of gingival bleeding measured by BOP was very high $[4,6]$, and it was associated with the level of oral hygiene. In addition to this, a large burden of oral inflammation measured by ADS was associated with poor oral hygiene. This indicates a great need for oral treatments such as restorative and periodontal care. Furthermore, polypharmacy and its side-effect of reduced salivation as well as swallowing difficulties were highly prevalent in the study population, consistent with earlier reports [5, 29]. Reduced salivation is a risk factor for caries and mucosal infections [3, 30]. In older persons with swallowing difficulties, good oral hygiene is essential to prevent both oral diseases and aspiration pneumonia [31]. Nursing staff must have the knowledge and ability to recognize early signs of residents' oral problems and diseases, and the possibility to refer residents to oral healthcare services. Thus, there needs to be higher priority and support for those providing oral care [32]. There was a mismatch between expressed oral hygiene measures being declared by staff against the findings of the levels of oral hygiene.

Our findings also suggest that poor oral hygiene of older care-dependent residents in long-term care facilities is correlated with poorer general HRQoL measured by the 15D instrument. Several studies have shown that OHRQoL and oral health problems are associated [3, 18, 33]. However, there is a scarcity of studies exploring the relationship between general HRQoL and oral health in long-term care settings. Furthermore, to our knowledge, no prior studies have investigated the relationship between oral hygiene and HRQoL. Some evidence suggests that receiving proper dental care and rehabilitation may improve HRQoL among long-term care residents $[34,35]$. Paying attention to oral hygiene and improving tooth brushing are practical and easy ways to enhance residents' HRQoL. Further research is needed to confirm these findings.

Good daily oral hygiene of dependent residents is the best way to prevent oral disorders. In our study, nurses reported that the teeth of most residents were brushed at least once a day. Clinical oral examination showed that the level of oral hygiene was poor since about $80 \%$ of residents had plaque on the surfaces of teeth. Our finding is in line with previous studies [9, 36, 37]. In addition, nearly $60 \%$ of residents had food debris in their mouth. Consistent 
with recent studies, residents with poor oral hygiene had significantly poorer cognitive status than those with better oral hygiene [7]. Previous studies have reported that caredependence was significantly associated with inadequate oral hygiene [10,11]. Our study population comprised old, cognitively impaired, and care-dependent residents, and in most cases the nursing staff performed daily tooth brushing. We did not find a statistically significant difference in the level of oral hygiene according to who performed the daily tooth brushing.

Our results suggest that adequate tooth brushing and oral hygiene are challenging in long-term care residents [38]. Personnel in long-term care facilities need training to enhance understanding of the impact of oral hygiene on oral health, general health, and quality of life of residents. Theoretical knowledge is the basis for improving oral hygiene and oral health in this population, but in itself is not sufficient to make the necessary changes. There is also a need for professional cooperation [39]. Oral healthcare professionals (dental hygienists and dentists) should provide hands-on guidance regarding oral hygiene procedures and discussions on oral care routines [40]. Nursing personnel also need to overcome barriers such as residents' responsive behaviors [41]. Dental hygienists can motivate and coach nursing personnel in long-term care facilities to tackle these difficulties [42]. Less than half of the residents had undergone an oral examination in the past year, despite having many risk factors for oral diseases, including impaired cognition, polypharmacy, and dry mouth.

\section{Conclusion}

Oral hygiene of dentate older people in long-term care is inadequate. Poor oral hygiene is associated with diminished HRQoL. Oral hygiene and HRQoL might be improved with oral care education of caregivers. Poor oral hygiene often indicates poor oral health. Thus, residents have a great risk of oral inflammation and a need for care from oral health professionals. Residents should have regular oral health check-ups.

Author contributions Conception or design: RKTS, KH, PM, KHP; Acquisition of data: RKTS, KH, HMR, PM, KHP; Statistical analysis: HK; Interpretation of data: RKTS, KH, PM, KHP; Drafting of the manuscript: RKTS, KHP; Critical revision of the manuscript for important intellectual content: all authors; Supervision: KHP; all authors read and approved the final manuscript.

Funding Open access funding provided by University of Helsinki including Helsinki University Central Hospital. This study was supported by Helsinki City and Helsinki University Hospital VTR.

\section{Declarations}

Conflicts of interest The authors have no conflicts of interest to declare.

Ethics approval The Ethics Committee of Helsinki University Hospital approved the study protocol. In addition, the City of Helsinki approved the study.

Consent to participate All participants or in case of significant cognitive decline (CDR 2-3) the closest proxy provided informed consent. This project adhered to the guidelines set forth by the Declaration of Helsinki and the Belmont Accord to ensure the safety of human research subjects.

Open Access This article is licensed under a Creative Commons Attribution 4.0 International License, which permits use, sharing, adaptation, distribution and reproduction in any medium or format, as long as you give appropriate credit to the original author(s) and the source, provide a link to the Creative Commons licence, and indicate if changes were made. The images or other third party material in this article are included in the article's Creative Commons licence, unless indicated otherwise in a credit line to the material. If material is not included in the article's Creative Commons licence and your intended use is not permitted by statutory regulation or exceeds the permitted use, you will need to obtain permission directly from the copyright holder. To view a copy of this licence, visit http://creativecommons.org/licenses/by/4.0/.

\section{References}

1. Griffin SO, Griffin PM, Li CH, Bailey WD, Brunson D, Jones JA (2019) Changes in older adults' oral health and disparities: 1999 to 2004 and 2011 to 2016. J Am Geriatr Soc 67:1152-1157

2. Saarela RKT, Hiltunen K, Mäntylä P, Pitkälä KH (2020) Changes in institutionalized older people's dentition status in Helsinki 2003-2017. J Am Geriatr Soc 68:221-223

3. Porter J, Ntouva A, Read A, Murdoch M, Ola D, Tsakos G (2015) The impact of oral health on the quality of life of nursing home residents. Health Qual Life Outcomes 13:102

4. De Visschere L, Janssens B, De Reu G, Duyck J, Vanobbergen J (2016) An oral health survey of vulnerable older people in Belgium. Clin Oral Investig 20(8):1903-1912

5. Janssens B, Vanobbergen J, Petrovic M, Jacquet W, Schols JMGA, De Visschere L (2017) The oral health condition and treatment needs assessment of nursing home residents in Flanders (Belgium). Community Dent Health 34:143-151

6. Yoon MN, Ickert C, Slaughter SE, Lengyel C, Carrier N, Keller $\mathrm{H}$ (2018) Oral health status of long-term care residents in Canada: results of a national cross-sectional study. Gerodontology 35:359-364

7. Lauritano D, Moreo G, Della Vella F, Di Stasio D, Carinci F, Lucchese A, Petruzzi M (2019) Oral health status and need for oral care in an aging population: a systematic review. Int J Environ Res Public Health 16:4558

8. Glick M, Monteiro da Silva M, Seeberger GK, Vision FDI et al (2020) shaping the future of oral health. Int Dent $\mathbf{J}$ 2012(62):278-291

9. Hopcraft MS, Morgan MV, Satur JG, Wright FA, Darby IB (2012) Oral hygiene and periodontal disease in Victorian nursing homes. Gerodontology 29:e220-e228 
10. Philip P, Rogers C, Kruger E, Tennant M (2012) Oral hygiene care status of elderly with dementia and in residential aged care facilities. Gerodontology 29:e306-e311

11. Niesten D, Witter DJ, Bronkhorst EM, Creugers NHJ (2017) Oral health care behavior and frailty related factors in a caredependent older population. J Dent 61:39-47

12. Cornejo-Ovalle M, Costa-de-Lima K, Pérez G, Borrell C, Casals-Peidro E (2013) Oral health care activities performed by caregivers for institutionalized elderly in Barcelona-Spain. Med Oral Patol Oral Cir Bucal 18:e641-649

13. de Visschere L, de Baat C, De Meyer L et al (2015) The integration of oral health care into day-to-day care in nursing homes: a qualitative study. Gerodontology 32:115-122

14. Willumsen T, Karlsen L, Naess R, Bjørntvedt S (2012) Are the barriers to good oral hygiene in nursing homes within the nurses or the patients? Gerodontology 29:e748-e755

15. Zenthöfer A, Meyer-Kühling I, Hufeland AL, Schröder J, Cabrera T, Baumgart D, Rammelsberg P, Hassel AJ (2016) Carers' education improves oral health of older people suffering from dementia-results of an intervention study. Clin Interv Aging 11:1755-1762

16. Schwindling FS, Krisam J, Hassel AJ, Rammelsberg P, Zenthöfer A (2018) Long-term success of oral health intervention among care-dependent institutionalized seniors: findings from a controlled clinical trial. Community Dent Oral Epidemiol 46:109-117

17. Wong FMF, Ng YTY, Leung WK (2019) Oral health and its associated factors among older institutionalized residents—a systematic review. Int J Environ Res Public Health 16:4132

18. Klotz AL, Hassel AJ, Schröder J, Rammelsberg P, Zenthöfer A (2017) Oral health-related quality of life and prosthetic status of nursing home residents with or without dementia. Clin Interv Aging 12:659-665

19. Folstein FM, Folstein SE, McHugh PR (1975) Mini-mental state: a practical method for grading the cognitive state of patients for the clinician. J Psychiatr Res 12:189-198

20. Hughes CP, Berg L, Danziger WL, Coben LA, Martin RL (1982) A new clinical scale for the staging of dementia. Br J Psychiatry 140:566-572

21. Vellas B, Guigoz Y, Garry P et al (1999) The mini nutritional assessment (MNA) and its use in grading the nutritional state of elderly patients. Nutr 15:116-122

22. Sintonen $H$ (2001) The $15 \mathrm{D}$ instrument of health-related quality of life: properties and applications. Ann Med 33(5):328-336

23. Loe H (1967) The gingival index, the plaque index, and the retention index systems. Periodontol 38:610-616

24. Osailan SM, Pramanik R, Shirlaw P, Proctor GB, Challacombe SJ (2012) Clinical assessment of oral dryness: development of a scoring system related to salivary flow and mucosal wetness. Oral Surg Oral Med Oral Pathol Oral Radiol 114:597-603

25. Janket SJ, Qvarnstrom M, Meurman JH, Baird AE, Nuutinen P, Jones JA (2004) Asymptotic Dental Score and prevalent coronary heart disease. Circulation 109:1095-1100

26. Saarela RKT, Muurinen S, Suominen MH, Savikko NN, Soini H, Pitkälä KH (2017) Changes in malnutrition and quality of nutritional care among aged residents in all nursing homes and assisted living facilities in Helsinki 2003-2011. Arch Gerontol Geriatr 72:169-173

27. Griffiths AW, Smith SJ, Martin A, Meads D, Kelley R, Surr CA (2020) Exploring self-report and proxy-report quality-of-life measures for people living with dementia in care homes. Qual Life Res 29(2):463-472

28. Aarabi G, Eberhard J, Reissmann DR, Heydecke G, Seedorf U (2015) Interaction between periodontal disease and atherosclerotic vascular disease-Fact or fiction? Atherosclerosis 241(2):555-560

29. Jokanovic N, Tan EC, Dooley MJ, Kirkpatrick CM, Bell JS (2015) Prevalence and factors associated with polypharmacy in longterm care facilities: a systematic review. J Am Med Dir Assoc 16(535):e1-12

30. Turner MD, Ship JA (2007) Dry mouth and its effects on the oral health of elderly people. J Am Dent Assoc 138(Suppl):15S-20S

31. Pace CC, McCullough GH (2010) The association between oral microorgansims and aspiration pneumonia in the institutionalized elderly: review and recommendations. Dysphagia 25(4):307-322. https://doi.org/10.1007/s00455-010-9298-9 (Epub 2010 Sep 8 PMID: 20824288)

32. Lindqvist L, Seleskog B, Wårdh I, von Bültzingslöwen I (2013) Oral care perspectives of professionals in nursing homes for the elderly. Int J Dent Hyg 11(4):298-305

33. Locker D, Matear D, Stephens M, Jokovic A (2002) Oral healthrelated quality of life of a population of medically compromised elderly people. Community Dent Health 19:90-97

34. Ilhan B, Cal E, Dundar N, Guneri P, Daghan S (2015) Oral healthrelated quality of life among institutionalized patients after dental rehabilitation. Geriatr Gerontol Int 15:1151-1157

35. Naito M, Kato T, Fujii W, Ozeki M, Yokoyama M, Hamajima N, Saitoh E (2010) Effects of dental treatment on the quality of life and activities of daily living in institutionalized elderly in Japan. Arch Gerontol Geriatr 50:65-68

36. Peltola P, Vehkalahti MM, Wuolijoki-Saaristo K (2004) Oral health and treatment needs of the long-term hospitalised elderly. Gerodontology 21:93-99

37. Montal S, Tramini P, Triay JA, Valcarcel J (2006) Oral hygiene and the need for treatment of the dependent institutionalised elderly. Gerodontology 23:67-72

38. Wårdh I et al (2000) Oral health care-a low priority in nursing. In-depth interviews with nursing staff. Scandinavian J Caring Sci 14:137-142

39. Volk L, Spok M, Sloane PD, Zimmerman S (2020) Improving evidence-based oral health of nursing home residents through coaching by dental hygienists. J Am Med Dir Assoc 21:281-283

40. Seleskog B, Lindqvist L, Wårdh I, Engström A, von Bültzingslöwen I (2018) Theoretical and hands-on guidance from dental hygienists promotes good oral health in elderly people living in nursing homes, a pilot study. Int J Dent Hyg 16:476-483

41. Hoben M, Clarke A, Huynh KT, Kobagi N, Kent A, Hu H, Pereira RAC, Xiong T, Yu K, Xiang H, Yoon MN (2017) Barriers and facilitators in providing oral care to nursing home residents, from the perspective of care aides: a systematic review and meta-analysis. Int J Nurs Stud 73:34-51

42. Janssens B, Vanobbergen J, Lambert M, Schols JMGA, De Visschere L (2018) Effect of an oral healthcare programme on care staff knowledge and attitude regarding oral health: a nonrandomised intervention trial. Clin Oral Investig 22:281-292

Publisher's Note Springer Nature remains neutral with regard to jurisdictional claims in published maps and institutional affiliations. 


\section{Affiliations}

\section{Riitta K. T. Saarela ${ }^{1}$ D $\cdot$ Kaija Hiltunen ${ }^{2}$ (D) Hannu Kautiainen ${ }^{3,4}$ (D) Hanna-Maria Roitto ${ }^{5}$ - Päivi Mäntylä ${ }^{6,7}$.} Kaisu H. Pitkälä8,9

1 Department of Social Services and Health Care, City of Helsinki, Oral Health Care, P.O. Box 6009, 00099 Helsinki, Finland

2 Department of Oral and Maxillofacial Diseases, Faculty of Medicine, University of Helsinki, Helsinki, Finland

3 Primary Health Care Unit, Kuopio University Hospital, Kuopio, Finland

4 Folkhälsan Research Center, Helsinki, Finland

5 Department of Social Services and Health Care, City of Helsinki, Geriatric Outpatient Clinic, Helsinki, Finland
6 Institute of Dentistry, University of Eastern Finland, Kuopio, Finland

7 Kuopio University Hospital, Oral and Maxillofacial Diseases, Kuopio, Finland

8 Department of General Practice and Primary Health Care, University of Helsinki, Helsinki, Finland

9 Helsinki University Hospital, Unit of Primary Health Care, Helsinki, Finland 